\title{
PSICOLOGIA, SAÚDE E TRABALHO: DA EXPERIÊNCIA AOS CONCEITOS
}

\author{
Admardo Bonifácio Gomes Júnior ${ }^{1}$ \\ Universidade Estadual de Minas Gerais, Belo Horizonte-MG, Brasil \\ Yves Schwartz \\ Aix-Marseille Université, France
}

Este ensaio busca debater sobre o papel da Psicologia em uma ação cidadã à luz da démarche ergológica. Interessa-nos aqui discutir e responder às seguintes perguntas: como reconstruir a atividade da Psicologia diante das demandas sempre reconfiguradas em cada momento e lugar histórico? Como permitir que a atividade do trabalhador "psi" se deixe instruir pela singularidade de suas experiências clínicas?" Será que o estudo do trabalho humano empreendido pela ergologia poderia contribuir no enfrentamento dos atuais desafios à prática "psi"?

Pensar as possíveis contribuições da ergologia para uma ação cidadã no campo "psi" nos exige lançar luz sobre a relação sempre problemática entre o psíquico e o social. Abordar este problema aqui nos leva a alguns possíveis percursos.

- Num primeiro momento acreditamos necessária a explicitação do modo como a ergologia chegou ao ponto de encarar em parte tal problemática elegendo aí um ponto de báscula que articula e distingue o que é e o que se passa pelas vertentes psíquica e social da norma, ou seja, como ela localiza neste ponto um debate de normas e como a formulação da noção de dramáticas do uso do corpo-si busca preservar a riqueza daquilo que se acredita estar aí em jogo.

- Em seguida nosso estudo busca explicitar uma exigência metodológica que se reconhece por clínica na démarche ergológica, destacando aí a atenção que devemos reservar aos riscos do que George Canguilhem chamou de usurpação do espaço do conhecimento.

- Finalmente, parece-nos coerente questionar o que tudo isso pode apontar como via para uma atividade "psi" cidadã, por isso traremos algumas contribuições desenvolvidas no campo da psicanálise que acreditamos importante serem debatidas com outros campos "psi".

Tentaremos, assim, percorrer estes três caminhos em busca de orientações que nos permitam muito mais levantar questões sobre uma atividade "psi" cidadã do que indicar aí one best way.

\section{DRAMÁTICAS DO USO DO CORPO-SI: DEBATES DE NORMAS SOCIAIS E PSÍQUICAS}

A ergologia, partindo das mutações do trabalho humano observadas quando da crise dos modos tayloristas de produção, toma como eixo de suas investigações 0 empreendimento humano na experiência do trabalho, demonstrando a amplitude de abordá-lo a partir do conceito de atividade. Este conceito é a espinha dorsal da démarche ergológica, em cujo centro se encontra o conceito de norma.

De forma simples, podemos pensar que há sempre um meio que propõe suas normas

1 Endereço para correspondência: Rua São João Evangelista, 525, ap. 101, Bairro Santo Antônio, CEP 30.330-140 Belo Horizonte-MG, Brasil.E-mail: admardo.junior@uol.com.br 
àqueles que lhe são internos (pensemos no campo privilegiado tomado pela ergologia: o meio de trabalho, onde se dá a experiência de trabalho stricto sensu). Entendemos por trabalho stricto sensu toda a prestação de serviço remunerada em uma sociedade mercantil e de direito pautada pelo dispositivo legal. Retomando, há toda uma gama de normas que antecedem qualquer experiência de trabalho, assim como há sempre renormalizações, que é o tratamento dado a tais normas por aqueles que as vivem. $A$ isso chamamos debate de normas. Este debate é empreendido pela entidade que em ergologia preferimos chamar de corpo-si, em vez de indivíduo, sujeito ou subjetividade, para fugir aos lugares-comuns, já bastante codificados, que tais termos historicamente portam.

Dizer que há sempre renormalizações (ou debates de normas) empreendidas por um corpo-si é uma forma de pôr em destaque também que há sempre uma posição ativa desta entidade, de livre disposição das capacidades, que se dá na forma de um uso: um uso do corpo-si, sempre por si, mas não sem o outro, sendo assim também pelo outro. É a dimensão do outro que propõe (pelas prescrições e obrigações do mundo do trabalho, pela transmissão, pela tradição, pela cultura, etc.) as normas antecedentes a toda e qualquer atividade humana. Podemos pensar na própria linguagem como um sistema de normas que nos é anterior e do qual fazemos uso transformando-o e transformando-nos mais ou menos.

O trabalho é reconhecido como um lugar de debate, de possibilidades, de negociações. Nele a pura e simples execução das prescrições é impossível, pois as normas são sempre renormalizadas, ressingularizadas. Feitas tanto da matéria da linguagem quanto de mimetismos e gestualidades, as prescrições são sempre transformadas pela atividade empreendida no uso do corpo-si para a efetivação do que os ergonomistas de tradição francesa há alguns anos reconhecem como trabalho real. Entre linguagem e atividade opera o que chamamos de uma dupla antecipação: por um lado, o uso da linguagem portando conceitos e saberes (e podemos pensar também em toda a gestualidade da linguagem corporal) busca antecipar a atividade prevendo, codificando de forma racional, servindo de modelo de modos operatórios e permitindo a transmissão e o acúmulo de experiências; e por outro, a própria atividade, que antecipa, em contrapartida, o que deve ser posto em palavras, formalizado em saberes e conceitos e desenvolvido em novos modos de operar com o corpo. Este é o cenário das dramáticas do uso do corpo-si, dos infinitos debates de normas, mesmo que infinitesimais, que o corpo-si, por um impulso de vida e de saúde, sintetiza em sua atividade.

Como vimos, o conceito de norma é um conceito essencial. É a partir dele que podemos definir debate de normas e localizar aí esta dobradiça entre o social e o psíquico com a noção de renormalização. É um conceito que talvez possa ultrapassar 0 dualismo - muito problemático no caminho da filosofia e das ciências sociais - entre o social e o individual, entre alma e corpo, entre a natureza e a cultura; mas é de perguntar: poderia este conceito de norma, como pouco a pouco a ergologia o tem desenvolvido, permitir tudo isso? $\dot{E}$ um pouco ambicioso, reconhecemo-lo, mas nos parece importante discuti-lo.

Nossa proposta é então tomar a noção de debate de normas como uma articulação integral entre o social e o psíquico. Esta hipótese supõe um exercício sobre as noções de normas, normas antecedentes e renormalização. Comecemos pela noção de norma, a dimensão social da norma e a reinstituição desta norma antecedente pelo psíquico. A norma é isso que é instituído na história, e isso vai diretamente designar o que é próprio à humanidade. Desde que há norma, de que há algo que é instituído na história, há humanidade. Certamente esta norma é instituída de diversas formas através da história. Se é a norma é algo próprio da humanidade, fica claro que ela se dá em diferentes dimensões, por exemplo, naquelas de uma sociedade de mercado e de direito, em outras, como a marcada pela escrita, pela fala articulada, pela interdição do incesto, etc. O que é próprio da sociedade humana é o fato de ela se fabricar, fabricar a sociedade, o que significa fabricar a norma. Numa sociedade de mercado e de direito convivemos com as normas jurídicas, técnicas, organizacionais, morais, da cultura, da linguagem - pois, como vimos, a linguagem é um sistema de normas. 
O problema é saber como se articulam estas diferentes normas.

Dito isso, acreditamos que podemos manter a ideia de que a norma é uma experiência especificamente antropológica. De certa forma, Freud (1930/1976b) se pôs esta mesma questão em "O mal-estar na civilização", onde ele nos fala do combate da cultura, ou seja, de um debate de normas empreendido entre o psíquico e o social. Há uma distinção importante entre a animalidade e a humanidade. A relação entre a animalidade e seu meio é uma relação de valor, mas uma relação que também é ligada a heranças genéticas. Se há debate de normas é porque não somos animais nem máquinas, nós criamos nosso mundo. O mesmo podemos afirmar, ainda com a psicanálise, quanto à sexualidade: ela é sempre retrabalhada por toda uma série de normas e renormalizações singulares.

Por natureza entendemos um meio de normalidades sem renormalização. É O natural. A experiência da renormalização é especificamente antropológica ou cultural. É o conceito de norma que, através da noção de debate de normas, vai fazer a articulação entre a integralidade do social e a integralidade do psíquico ou do corpo. É o ponto de encontro com todas as psicologias que se reconhecem como sendo sempre uma psicologia social, como nos afirma Freud (1921/1976a) em "Psicologia de grupo e análise do ego".

O que faz a articulação entre a vertente social da norma e a vertente psíquica é o debate de normas com o impossível e o invivível das normas antecedentes; ou seja, há uma impossibilidade vital no humano de restringir sua atividade às normas. Há no humano uma prioridade de infringir. Não por acaso Freud vai distinguir pulsão de instinto. No nível instintual, como no animal, o comportamento se restringe às normas, mas o nível pulsional vem exatamente apontar para algo que foge à norma, que a infringe.

Entre a infração e a norma não podemos saber o que vem primeiro. Se há história humana, se há uma sucessão de instituições (porque cada grupo humano tem seu sistema de normas mais ou menos próximo ou oposto ao dos grupos vizinhos) é porque não há norma sem tomada de posição em relação a ela, sem diferentes graus de aceitação e de rejeição. Não há debate de normas sem tomada de posição em relação às normas. Não há nenhuma naturalidade de uma norma, qualquer que seja, em meio social. Esta talvez seja a singular contribuição da ergologia neste debate: há normas antecedentes, o mundo humano é um mundo normatizado, mas ao mesmo tempo, impossível e invivível. É impossível e invivível que o mundo de normas antecedentes seja objeto de pura aplicação no humano. É invivível justamente porque a saúde, no sentido canguilheniano, não é uma decorrência do meio, mas a expressão da tentativa, de um esforço em recriá-lo. O invivível é a herança da vida em nós. A saúde é a experiência para todos os viventes de sua relação com o meio (positiva ou negativa), mas este meio é um meio histórico-social, ou seja, não é um umwelt animal. Esta é a experiência especificamente antropológica da saúde: a de arriscar a propor sempre a seu meio de normas antecedentes suas próprias normas de saúde. Canguilhem (1947/2001) reafirma esta ideia fazendo uma análise do Taylorismo e afirmando que a reação a este é não só social, mas também de saúde. A resistência do vivente, que não está inscrita na natureza, é uma resistência a uma imposição do meio humano como um meio de normas, esta é sua diferença com a animalidade.

A maneira propriamente ergológica de pensar tudo isso, toda esta forma de pôr em história as normas, é que, se há forçosamente infração e história, é porque há forçosamente este debate de normas entre as normas antecedentes e o impossível/invivível. Há um conjunto mais ou menos articulado, mais ou menos coerente de normas antecedentes (porque não é necessariamente coerente nem articulado), e este conjunto a cada momento é rejulgado, retrabalhado por este debate empreendido pela entidade humana que chamamos de corpo-si, que podemos dizer, em todos os graus entre consciente e inconsciente, entre o infinitesimal e o global, entre o biológico e o cultural. É o que faz história.

\section{A CLÍNICA E O RISCO DA “USURPAÇÃO” DO CONHECIMENTO}

Todo este raciocínio, esses conceitos e argumentações, desenvolvidos sob a nomeação de ergológicos, portam a herança 
de antecessores que chamamos os três médicos atípicos: Alain Wisner, Ivar Oddone e George Canguilhem (Schwartz, 2010). É das experiências destes médicos que a ergologia retira o que reconhece como uma obrigação clínica; uma obrigação que apresenta sua faceta epistêmica por exigir que os conceitos sejam sempre confrontados ao aqui-e-agora da experiência sempre singular quando envolve processos de renormalização operada pelo corpo-si: "A clínica é esta insubstituível confrontação a individualidade biológica sempre singular e os conceitos elaborados a partir das situações standard" (Schwartz, 2000, p. 405, tradução nossa).

Toda ciência cujos conceitos incluam a atividade humana deve estar atenta a esta obrigação para não incorrer no risco de uma usurpação do conhecimento. Expliquemo-nos melhor. Toda esta questão eminentemente epistêmica da produção dos conceitos pode ser pensada a partir do conceito de atividade. Algumas ciências estudam objetos sem atividade (no sentido ergológico, ou seja, sem debate de normas). Pensemos aqui, por exemplo, nos conceitos que integram a lei da queda dos corpos, o princípio da inércia, o conceito de calor específico, o DNA, etc.: são conceitos que estão em total desaderência ao espaço e ao tempo, ou seja, sua validade está disjunta do momento e do lugar que se encontra em causa.

Por outro lado, encontramos ciências que estudam objetos com atividade, ou seja, ciências cujos conceitos, mesmo estando sujeitos ao debate de normas por incluírem a atividade humana, visam neutralizar a variabilidade de suas interferências. Estas ciências se apresentam sob a forma de normas da vida social que se cristalizam em conceitos, leis, regulamentos e procedimentos, como o sistema jurídico, as regras do urbanismo, as normas de segurança, os contratos de trabalho, os organogramas empresariais, etc. O objeto da norma jurídica, por exemplo, é sempre mais ou menos vivo e engendrado pelos debates daqueles que a vivem.

Nas disciplinas que conhecemos sob 0 título de humanas e sociais, cujos conceitos visam ao conhecimento da alteridade, a atribuição do termo ciência deve ser entendida como reivindicação. São disciplinas cujos conceitos não buscam normatizar, mas conhecer os fenômenos humanos. Nelas o pressuposto de modelização possível dos comportamentos humanos aumenta o risco de uma instrumentalização que legitimaria sua deriva para usos não sadios ou usurpados dos conceitos. Tais derivas limitam a possibilidade de os usos de si operarem renormalizações necessárias à saúde. A usurpação limita (ou até mesmo retira) uma parte legítima do direito de uso do corpo-si por si.

Aqui podemos trazer do mundo do trabalho alguns exemplos de um uso usurpado dos conceitos: tomar a noção de competência neutralizando ou subdimensionando a dimensão histórica e de valores que ela sempre comporta; o gerenciamento baseado em teorias de motivação, ou ainda, nas teorias econômicas baseadas no homo economicus; alguns processos de avaliação do desempenho que se limitam a reconhecer apenas a tentativa de adaptação da atividade à prescrição. Outros exemplos ainda de uso usurpado dos conceitos podem ser retirados da própria tentativa de taylorização dos processos de trabalho.

Frequentemente é o processo histórico de um conceito que nos permite localizar suas usurpações. Tomemos noutro campo o exemplo do conceito de homoerotismo: lidas sob a chancela do conceito de homossexualismo, as práticas homoeróticas foram por muito tempo patologizadas e sujeitas a tratamentos médicos e psicológicos, o que hoje nos parece inadmissível. Outro exemplo ainda, este mais contemporâneo: podemos pensar em como o conceito de depressão tem sofrido derivas a ponto de - em alguns casos, mas não poucos - os sentimentos de tristeza não encontrarem mais espaços de legítima expressão em nossa sociedade, chegando ao ponto de serem tratados medicamentosamente.

É exatamente contra este tipo de risco de usurpação que a clínica é requerida na démarche ergológica como uma obrigação. É uma obrigação ética e científica. Ela busca preservar o debate eminentemente humano sobre as normas que compõem seu meio. Ela marca a impossibilidade de se modelar, antecipar ou explicar de maneira satisfatória a alteratividade a partir de hipóteses gerais e/ou anteriores ao evento, exatamente por buscar preservar as singularidades destes eventos. A construção dos conceitos sob a perspectiva 
clínica impõe situar em seu seio o momento da experiência e o exercício da capacidade de se desprender de prévias categorias, em um esforço de certo desconforto intelectual. Busca aproximar-se ao máximo da experiência nas atividades humanas, dos debates de normas e ressingularizações que cada atividade engendra.

$\mathrm{Na}$ ergologia o epistêmico, ligado ao objetivo de conhecer, é sempre pensado em sua relação com o transformativo, ou seja, o agir que modifica o estado das coisas. Toda atividade conjuga essas duas dimensões, e o que se busca em uma clínica de abordagem ergológica é o reconhecimento dos diferentes saberes (constituídos e investidos), assim como a possibilidade de deslocá-los quando postos em debate. $O$ dispositivo clínico que a démarche ergológica se propõe a trabalhar é o chamado Dispositivo dinâmico a três polos (DD3P), um dispositivo clínico de intervenção, produção e circulação de saberes que visa ampliar a margem de manobra na lacuna entre as normas antecedentes do trabalho $e$ as possibilidades de renormalização dos sujeitos expressas nas dimensões do uso do corpo-si (por si e pelo outro).

No DD3P, em um primeiro polo situamos os saberes armazenados pelo patrimônio conceitual das disciplinas, os saberes constituídos, os patrimônios conceituais; num segundo polo localizamos os saberes investidos no exercício das atividades, constituídos e transmitidos pelas experiências sempre singulares e que se apresentam mais ou menos formalizados, mais ou menos conscientes. Por sua vez, o terceiro polo é requerido como esta exigência de postura ética e epistemológica que busca preservar a tensão e o diálogo entre os dois primeiros como única possibilidade de fazer avançar a constituição de saberes. Os saberes constituídos são postos em debate com os saberes investidos para que, neste exercício, ambos possam munir-se de possibilidades de avanços e mudanças.

São múltiplas as possibilidades de uso da ergologia e do DD3P. Também chamados de dispositivos socrático de mão dupla, apresentam a orientação inversa àquela de uma perspectiva taylorista, que parte de pressupostos redutores voltados à implementação de uma forma idealizada de governo do trabalho humano. São dispositivos matriciais e podem apresentar geometria variável, com funções que se ajustam às demandas localizadas e diferenciadas no tempo e no espaço. Por exemplo, podem ter função mais formadora se o que se busca é a formação, mais profissionalizante, se o que se quer é preparar para um ofício ou voltar-se para a busca de soluções operacionais; e até mesmo podemos pensar em efeitos terapêuticos se o que se busca é o restabelecimento ou a promoção da saúde (cf. Schwartz, 2002).

\section{POR UMA ATIVIDADE "PSI” CIDADÃ}

Poderia a prática das disciplinas "psi", se preservarmos a orientação ergológica, abrir mão desta obrigação clínica? Que relações podem ser estabelecidas entre uma obrigação clínica e uma atividade cidadã no campo "psi"? Queremos aqui defender que para qualquer disciplina "psi" o retrabalho contínuo dos conceitos que as instrumentalizam é uma exigência vital e ética, porque, por um lado, a característica mesma de seu objeto de estudo é extremamente sensível aos debates de normas, e por outro, essas disciplinas reivindicam para si (em alguns casos) o estatuto de ciência. Por isso os profissionais "psi" não podem desautorizar-se de tocar nos axiomas fundamentais da ética, do direito e da política, discutindo-os e problematizando-os. As disciplinas "psi" não devem resistir, sob o risco de se tornarem autoimunes, às demandas sempre renovadas das políticas públicas, dos adolescentes em conflito com a lei, das discussões sobre as psicopatologias, da economia solidária, das sexualidades contemporâneas, da saúde do trabalhador, dos desafios dos direitos humanos, da formação profissional - enfim, do exercício contínuo das questões sobre a psicologia que existe e a psicologia que queremos construir. Os conceitos neste campo do conhecimento devem apresentar a fluidez que lhes permita um contínuo deslocamento na história. O movimento descrito neste deslocamento histórico muitas vezes nos é mais instrutivo, do ponto de vista dos fenômenos que eles tentam explicar, do que propriamente os enunciados estanques em suas conceituações. Para tomarmos como exemplo, o conceito de sintoma na psicanálise nos parece paradigmático (cf. Gomes Júnior, 2013). O conceito de sintoma, com Freud, deixa de ser 
compreendido como uma disfunção e passa a apontar o modo de funcionamento de um conflito psíquico. Com o intuito inicial de eliminá-lo, a psicanálise contemporânea pretende permitir ao sujeito saber fazer com o sintoma. $\mathrm{O}$ que fez o trabalho analítico de escuta das experiências vividas e narradas sob transferência foi permitir avançar o conceito, a compreensão e o manejo do que se apresenta sob a noção de sintoma. Esse movimento da disciplina psicanalítica marca como o "plano ergológico" (mesmo que não reconhecido por esta denominação) a fez trabalhar na produção e no uso de seus conceitos sob a prioridade da experiência e da atividade aí em jogo.

Como nos adverte Lacan (1953/1998, p. 322), deve renunciar à prática da psicanálise "... quem não conseguir alcançar em seu horizonte a subjetividade de sua época". Como podemos escutar esta advertência de Lacan? Qual subjetividade se encontra no horizonte (aqui e agora) de cada "psi"? E alcançá-la para quê?

Uma resposta possível, pelo menos para o psicanalista, passa pelo reconhecimento de que ele pode "ajudar a civilização a respeitar a articulação entre normas e particularidades individuais", sendo "sensível às formas de segregação" (Laurent, 2007, p. 144). Dito de forma ergológica: o analista pode atentar para os dramas do uso do corpo-si que se produzem singularmente e as possíveis formas usurpadas que tentam enquadrá-los limitando suas possibilidades de renormalização. Laurent (2007) ainda nos adverte: "Não se deve tirar de alguém sua particularidade, a fim de misturá-lo com todos no universal, em razão de algum humanitarismo ou qualquer outro motivo." ( $p$. 145); e prossegue:

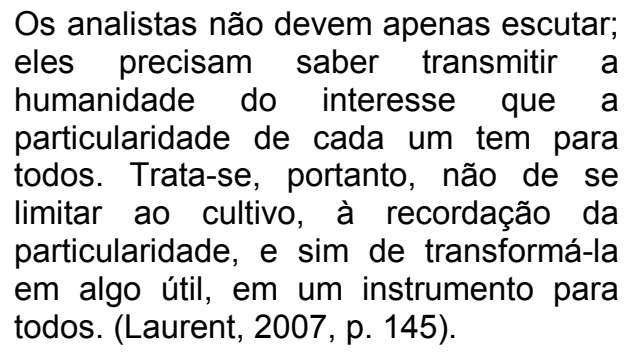

Ou seja, de permitir um uso, um emprego, uma forma útil da singularidade, do uso do corpo-si no campo do outro.

Com a psicanálise podemos dizer que cada civilização cria suas modalidades de gozo, ou seja, ofertas da própria cultura orientadas a uma satisfação possível da pulsão. Podemos reconhecer em nossas sociedades atuais estas ofertas no consumo (oral), na acumulação (anal), na onipresença do olhar e da voz. São possibilidades de gozo, lugares e temporalidades onde certa transgressão é tolerada. São formas prêt-à-porter que buscam organizar as normas e os modos de transgredilas, mas, como nos lembra Kehl (2009), a cada "nova abundância, novos males" (p. 27): excluídos que reivindicam o direito ao gozo e incluídos impotentes em se saciar. Cada civilização cria assim seus restos que não são simbolizados pela norma social. Esta é a matéria-prima do trabalho "psi", que exige destes profissionais a escuta clínica, um a um, de cada uso do corpo-si, da singularidade da posição subjetiva e de suas manifestações sintomáticas.

$O$ que a ergologia pode oferecer como contribuição com as disciplinas "psi" aponta para sua relação com as ciências. À ergologia interessa uma postura clínica que questione o saber científico, que possa fazer avançar o ponto-limite de cada ciência, seu limite lógico. As possibilidades de renormalizações empreendidas pelo corpo-si devem retornar aos patrimônios do saber em questão, mas não sem alojar aí a dimensão sempre presente do impossível e do invivível. Este é o ponto ético da ergologia; ponto que lhe permite estar atenta à usurpação dos conceitos.

Para concluir podemos afirmar: Uma prática "psi" cidadã e ergológica deve estar atenta às relações intrínsecas entre as ciências e as subjetividades que se produzem em cada tempo e lugar.

\section{REFERÊNCIAS}

Canguilhem, G. (2001). Meio e normas do homem no trabalho. Proposições, 12(2-3), 35-36. (Trabalho original publicado em 1947).

Canguilhem, G. O conhecimento da vida. Rio de Janeiro: Forense Universitária, 2012.

Freud, S. (1976a). Psicologia de grupo e a análise do ego. In: J. Strachey (Ed. e J. Salomão, Trad.), Edição Standard Brasileira das Obras Completas de Sigmund Freud. (Vol. 18, pp. 89-179). (Original publicado em 1921).

Freud, S. (1976b). O mal-estar na civilização. In: J. Strachey (Ed. e J. Salomão, Trad.), Edição Standard Brasileira das Obras Completas de Sigmund Freud. (Vol. 21, pp. 81-171). Rio de Janeiro, Imago. (Original publicado em 1930). 
Gomes Júnior, A. B. (2013). L'usage de soi et le savoir y faire avec le symptôme au travail. Thèse en cotutelle: Aix Marseille Université \& Universidade Federal de Minas Gerais.

Kehl, M. R. (2009). O tempo e o cão: a atualidade das depressões. São Paulo: Boitempo.

Lacan, J. (1998). Função e campo da fala e da linguagem. In J. Lacan. Escritos (pp. 238-324). Rio de Janeiro: Jorge Zahar. (Original publicado em 1953).

Laurent, É. (2007). O analista cidadão. In É. Laurent. A sociedade do sintoma: a psicanálise hoje (pp.141-150). Rio de Janeiro: Contra Capa Livraria.

Schwartz, Y. (1992). Travail et Philosophie: convocations mutuelles. Toulouse: Octares.
Schwartz, Y. (2000). Le paradigme ergologique ou um métier de Philosophe. Paris: Octares.

Schwartz, Y. (2002). Disciplina epistêmica disciplina ergológica - paideia e politeia. Pro-Posições, Campinas, 13(1), 126-149.

Schwartz, Y. (2010). Quel sujet pour quelle experience? Travail et Apprentissages, (6), 6-24.

Recebido em 22/10/2013 Aceito em 07/08/2014

Admardo Bonifácio Gomes Júnior: doutor em Educação pela Universidade Federal de Minas Gerais e em Filosofia pela Aix-Marseille Univesité, pós-doutorando na Faculdade de Educação da Universidade Federal de Minas Gerais, Brasil.

Yves Schwartz: professor emérito do instituto de Ergologia da Aix-Marseille Université e do CNAM (Paris), membro do CNRS, França. 